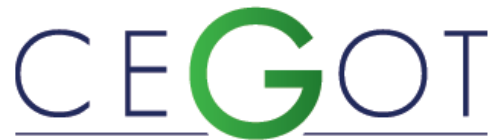

Centro de Estudos de Geografia e Ordenamento do Território
ALMEIDA, LINDIJANE

Universidade Federal do Rio Grande do Norte

Departamento de Políticas Públicas

59148-676, Rua Rio Taquari, no 41, Emaus, Natal, Brasil

almeida.lindijane@gmail.com

FERREIRA, GLENDA

Universidade Federal da Paraíba Departamento de Gestão

Pública

58051-900, João Pessoa, Brasil

glenda.dpp@hotmail.com

SILVEIRA, RAQUEL

Universidade Federal do Rio Grande do Norte

Departamento de Políticas Públicas

59020-300, Natal, Brasil

raquelmcsilveira@hotmail.com

COSTA, THAYSA

Universidade Federal do Rio Grande do Norte

Departamento de Políticas Públicas

59052-700, Natal, Brasil

thaysa belo15@hotmail.com

\title{
Os movimentos sociais urbanos em Natal/RN: uma análise sobre a Primavera de Junho na Cidade do Sol
}

Urban social movement in Natal-Rio Grande do Norte-Brazil: an analysis of the "Spring of June" at Cidade do SoI

Referência: Almeida, Lindijane et al. (2018). Os movimentos sociais urbanos em Natal/RN: uma análise sobre a Primavera de Junho na Cidade do Sol. Revista de Geografia e Ordenamento do Território (GOT), n. ${ }^{\circ} 13$ (junho). Centro de Estudos de Geografia e Ordenamento do Território, p. 7-32, dx.doi.org/10.17127/got/2018.13.001

\section{RESUMO}

Ao longo das últimas décadas, uma onda de manifestações reivindicatórias ganhou força no Brasil. Nesse contexto, após junho de 2013, o padrão de organização da sociedade brasileira sofreu modificações. Embora os novos movimentos sociais sejam caracterizados, em geral, por possuírem inúmeras motivações, entende-se que eles demonstram especificidades, principalmente no que tange ao seu modo de atuação no espaço urbano. Nesse sentido, o artigo objetiva traçar um panorama dos movimentos sociais urbanos na cidade de Natal/RN, entre 2013 e 2016. O caminho metodológico foi dividido em dois momentos, pesquisa de mídia em jornais de circulação nacional e entrevistas semiestruturadas com representantes locais dos movimentos sociais. A pesquisa evidenciou movimentos com características diversas e que apresentam convergências pontuais na sua atuação.

Palavras-chave: Direito à cidade. Movimentos sociais. Mobilidade urbana. Direito à moradia. 


\section{ABSTRACT}

Over the last decades, a number of civil society protests have gained momentum in Brazil. In this context, after these protests in June of 2013 there were alterations in organizational pattern of the Brazilian civil society. Although the new social movements are generally characterized by a great number of different motivations, it is understood that these movements demonstrate specificities that deserve to be analyzed, especially the ones related to how these issues influence urban space. In this sense, the article aims to draw a panorama of urban social movements in the city of Natal / RN, between 2013 and 2016. Thus, a research was done considering data from two national newspapers and was also based on semi-structured interviews realized with local social movement representatives. The research evidenced movements with different characteristics and that have specific convergences.

Keywords: City rights. Social movements. Urban mobility. Housing rights.

\section{Introdução}

As Ciências Sociais, em especial a Sociologia Urbana, há tempos chamam a atenção para o papel dos movimentos sociais na contemporaneidade, ressaltando a sua posição enquanto um dos atores centrais nos processos reivindicatórios que buscam alcançar transformações relacionadas à ideia da concretização de direitos e da efetivação da justiça social.

Em nível mundial, observam-se, nos últimos anos, esforços notáveis de construção de novos modelos de democracia mais republicanos e igualitários. As novas leituras acerca da relação Estado/sociedade expressam um esforço teórico que vem ganhando força nos debates mais recentes acerca da democracia contemporânea. Tal esforço tem apontado para os limites da polarização entre participação social e representação política, e as implicações que isso traz para a compreensão do funcionamento tanto das instituições representativas tradicionais (YOUNG, 2006), quanto para os novos arranjos institucionais que passam a incluir atores sociais no processo decisório de políticas públicas (LAVALLE; VERA, 2011).

De acordo com Miguel (2014), fica claro que nenhuma teoria democrática pode ser construída sem que se amplie seu alcance para além do momento eleitoral. As limitações da democracia que se propunha restrita ao voto, tornaram-se patentes, a partir dos anos de 1960, quando, progressivamente, assistiu-se ao declínio dos índices de comparecimento às eleições, às explosões de insatisfação e à ampliação da desconfiança em relação às instituições políticas. Tal situação fez com que, nos anos de 1970, o pensamento político 
buscasse retrabalhar o conceito de democracia, agora privilegiando a participação política popular (MIGUEL, 2014).

Como chama a atenção Miguel (2014, p. 97), “a representação é um mecanismo crucial para a manutenção do conflito social em níveis manejáveis, mas o preço que se paga é um desvio constante entre as ações dos representantes e as vontades dos representados", originandose, portanto, o que para o autor pode ser denominado como o desafio da representação democrática: "a redução do desvio entre esses dois polos". Como destaca o autor:

Da mesma maneira como a impossibilidade de tomada direta de decisões pelo povo torna imprescindível a representação parlamentar, a impossibilidade de uma discussão envolvendo a todos gera a necessidade da representação das diferentes vozes da sociedade no debate público (MIGUEL, 2003, p. 133).

De modo particular, a partir dos anos de 1990, diversos movimentos sociais começaram a questionar o modelo hegemônico de democracia (liberal-representativa) e ressaltar a necessidade de uma maior democratização. Essa discussão conduziu a uma revisita à teoria dos Movimentos Sociais, no que diz respeito ao seu próprio papel nas sociedades.

No Brasil, a institucionalização da participação social preconiza a ampliação do espaço público para a gestão democrática das cidades, a qual é reforçada com o Estatuto da Cidade (2001). Nesse contexto, como afirmou Cardoso (2012), a gestão democrática das cidades deve ser assegurada por meio da participação da população na produção de políticas públicas na área de desenvolvimento urbano.

A despeito dos avanços normativos e institucionais na Política Urbana nos anos 2000, recentemente, foi possível perceber, sobretudo no contexto de grandes eventos (como a Copa do Mundo FIFA 2014 e os Jogos Olímpicos 2016), a ocorrência de uma "onda" de mobilizações e manifestações reivindicatórias por parte da sociedade civil. Esta, sobretudo ao longo da última década, vem demonstrando a insatisfação com a democracia brasileira e com os rebatimentos disso no processo de produção de políticas públicas no espaço urbano, o qual não tem proporcionado, adequadamente, a justiça social e a efetivação do direito à cidade. Nesse contexto, destaca-se que, após as manifestações populares iniciadas a partir de 2011 e em junho de 2013, no Brasil, tornou-se notório que o padrão de organização da 
sociedade civil sofreu modificações. Isso, por sua vez, provocou alterações na relação entre Estado e sociedade que vinha sendo consolidada no país, principalmente pós-governo Lula ${ }^{1}$. Nessa conjuntura, várias foram as razões que, de maneira individual ou combinada, fomentaram a indignação popular. Entre essas, destacam-se: i) a crise de credibilidade da democracia representativa, diante dos casos corrupção na administração pública noticiados na mídia nacional e ii) a insatisfação com a prestação dos serviços públicos. Durante as mobilizações iniciadas em 2013, foi possível, ainda, detectar o debate em torno das mais diversas temáticas, dentre elas, a mobilidade urbana, a saúde, a educação, o direito à moradia e a defesa das causas ambientais.

Entretanto, apesar de uma aparente coesão entre tais movimentos que se destacaram a partir das jornadas de junho no Brasil, entende-se que, internamente, tais grupos apresentam especificidades que merecem ser destacadas. Nesse sentido, ressalta-se a ampliação da pauta de reivindicações por parte dos novos movimentos, bem como o seu modo de atuação no espaço urbano. Segundo Gohn (2010), o panorama geral dos movimentos sociais no início do século XXI estava organizado em torno de dez eixos temáticos das lutas e demandas dos movimentos sociais no Brasil, como por exemplo: a luta pela melhoria das condições de habitabilidade e participação na estrutura políticoadministrativa da cidade; as mobilizações em defesa das questões ambientais e do acesso à moradia, bem como movimentos que envolvem questões étnico-raciais e de gênero.

Esses movimentos, por sua vez, apesar da abertura de espaços participativos para a proposição de políticas públicas, desde o início da década de 1990, utilizaram outras estratégias além da participação nos conselhos gestores de políticas públicas. Nesse sentido, as mobilizações fomentadas pelos movimentos sociais, sobretudo, a partir de 2013, em um novo contexto - Era da informação - conferem fortes indícios de que se está diante de formas de engajamento cívico dotadas de características semelhantes às manifestações da Primavera Árabe, dos Indignados na Espanha e dos Estudantes no Chile. Desse modo, é sob essas novas configurações que serão sublinhadas, aqui, as manifestações no Brasil iniciadas a partir de junho de 2013. Conforme Vainer (2013, p.40), essas manifestações foram uma

\footnotetext{
${ }^{1}$ Governo que estimulou uma maior participação social no processo de decisão das políticas públicas, ou seja, observamos que a trajetória de ocupação de cargos por militantes de movimentos sociais, assim como a criação dos ConCidades tem seu auge a partir do início do Governo Lula, em 2003.
} 
resposta da sociedade em relação ao desafio imposto pela "cidade de exceção, pela cidadeempresa e pela democracia direta do capital. Eles agora as desafiam. Querem outra cidade, outro espaço público".

Outros autores, como Pinto (2012), chamam a atenção para a existência de uma nova forma de fazer política, a qual está atrelada a novidades presentes no contexto das manifestações, podendo-se citar: 1) a postura dos movimentos sociais em relação à sociedade e ao Estado, a qual muda em relação à reivindicação, ou seja, o apelo à sociedade civil agora é em busca de "democratizar a democracia"; 2) a presença da internet e do celular constitui a segunda novidade apontada pela autora, dada a sua importância à organização dos movimentos sociais em redes; 3 ) a liderança a ser realizada por jovens, que estavam fora do cenário da política; 4) a relação estabelecida entre os movimentos sociais e os espaços públicos, visto que a decisão das ocupações passou a ser uma marca dos novos movimentos; e 5) a capacidade agregadora de diferentes segmentos e um alastramento da própria luta (PINTO, 2012).

Diante desse cenário, o presente artigo objetiva traçar um panorama dos movimentos sociais urbanos em Natal/RN, a partir da pauta base de reivindicação engendrada no contexto da Jornada de Junho de 2013 no Brasil. Nesse sentido, questiona-se: quais as características dos movimentos sociais urbanos de Natal/RN no período de 2013 a 2016 ?

A análise proposta partirá do pressuposto de que, no recorte espacial estudado, os novos movimentos sociais não estabelecem diálogo entre si, são momentâneos e não horizontais. Assim, (1) não há uma convergência de ações entre os movimentos sociais de Natal, a despeito de tais grupos lutarem, ao mesmo tempo, e no mesmo território, pela coprodução de políticas públicas urbanas; (2) esses movimentos possuem uma atuação pontual e focalizada em determinados contextos e problemáticas específicas e (3) contam com lideranças definidas, que conduzem as atividades internamente, apesar de se constatar a presença de processos deliberativos.

A fim de realizar o estudo proposto, foi necessário dividir o caminho metodológico em dois momentos. Inicialmente, foi realizada uma pesquisa de mídia em dois jornais de circulação nacional, buscando identificar as duas temáticas principais que formavam a pauta das reivindicações dos movimentos sociais no Brasil em junho de 2013. O material pesquisado 
possui um recorte nacional e compreendeu notícias publicadas entre junho de 2013, (período em que se avolumaram as reivindicações no Brasil) e agosto de 2014 (após realização da Copa do Mundo FIFA 2014 - período de muita agitação, principalmente, nas cidades sede). Assim, foram analisadas 96 reportagens veiculadas nos jornais Folha de São Paulo e O Globo. A escolha dos jornais a serem pesquisados ocorreu com base no estudo do ranking dos jornais de maior circulação no Brasil, elaborado pela Associação Nacional de Jornais (ANJ). A observação da classificação dos jornais que ocuparam os dois primeiros lugares, nos anos de 2002 a 2014 (anos pesquisados pela associação), denotou que os jornais Folha de São Paulo e O Globo aparecem com maior frequência entre os de maior circulação, motivo pelo qual serão utilizados como fonte para a presente pesquisa. Após o recolhimento de 96 reportagens nos dois jornais selecionados, os registros das notícias foram inseridos numa base de dados construída no SPSS, realizando-se a sua análise a partir da observação das temáticas de reivindicação mais recorrentes entre os movimentos sociais urbanos. Em seguida, estabeleceu-se o ranking dos principais temas, sendo selecionados os dois mais citados no material jornalístico. A partir de tal critério de seleção, será dado destaque aos movimentos sociais que se relacionam à luta pela garantia do direito à moradia e à mobilidade urbana em Natal.

Considerando a eleição dos quatro principais grupos atuantes - Comitê Popular da Copa; Associação Potiguar dos Atingidos pelas Obras da Copa (APAC); Levante Popular da Juventude (LPJ) e Movimento de Luta nos Bairros, Vilas e Favelas (MLB) - as análises terão como base dados coletados por meio de entrevistas semiestruturadas realizadas entre os meses de maio a agosto de 2016 com representantes locais.

Como base teórica e metodológica, optou-se por utilizar Castells (2013), Gohn (2010 e 2012) e Pinto (2012), os quais possibilitam problematizar e compreender os movimentos sociais na contemporaneidade, suas características e principais resultantes. No presente estudo, optou-se por utilizar Castells (2013) como referência para análise dos dados coletados na experiência de Natal/RN, uma vez que ele contribui para a compreensão das configurações políticas e institucionais dos Movimentos Sociais.

O presente texto está dividido em três seções, além desta introdução. Na primeira seção, será tratada a temática da reforma urbana e o conteúdo do Estatuto da Cidade, dado o contexto de urbanização brasileira que ensejou a luta de movimentos sociais urbanos, 
responsáveis pela estruturação do texto constitucional referente à Política Urbana no Brasil. A segunda apresenta um balanço teórico-analítico dos movimentos sociais, isolando as interpretações sob a ótica das análises mais recentes da literatura brasileira. Parte-se do entendimento de que esses movimentos podem ser entendidos como ações sociais coletivas de caráter sociopolítico e cultural que viabilizam formas distintas de a população se organizar e expressar suas demandas (GOHN, 2010; 2012). Na prática, variam da simples denúncia à atuação direta no aparelho do Estado por meio da atuação nas instituições participativas (IPs). Na terceira seção, à luz da teoria de Castells (2013), busca-se, além de descrever as entidades/organizações e as suas relações em torno da construção do direito à cidade, identificar a articulação entre os movimentos sociais urbanos em Natal.

\section{A Reforma Urbana e o Estatuto das Cidades: rumo à gestão democrática}

O processo de urbanização brasileira ensejou um conjunto de transformações nas cidades, sobretudo entre 1960 e 2000. O crescimento da população em áreas urbanas, que atualmente representa mais de $80 \%$, não foi, por sua vez, acompanhado por uma adequada oferta e distribuição territorial de equipamentos sociais de uso coletivo e de serviços que pudesse atender à crescente demanda populacional. Nesse contexto, o agravamento das desigualdades socioespaciais - expressa em problemáticas como inadequação habitacional, na proliferação de assentamentos precários, e em uma mobilidade urbana deficiente, por exemplo - pode ser considerado um fenômeno marcante e intrínseco das grandes cidades (FERREIRA, 2009).

Esse agravamento explicita, em larga medida, a dificuldade do poder público de resolver tais problemas, assim como de gerir a dinâmica do espaço urbano, cada vez mais complexa e multifacetada. O pensar de modo mais sistemático acerca dos processos e das dinâmicas que incidem sobre o espaço urbano ganhou evidência na década de 1960, em particular quando ocorreram diversas mobilizações políticas que balizaram as discussões sobre a Reforma Urbana no Brasil, termo cunhado pela primeira vez em 1963 no Seminário de 
Habitação e Reforma Urbana. Entendia-se, nesse período, que o Estado precisava atuar no sentido de resolver os problemas urbanos. Segundo Klintowitz (2013, p. 5-6):

As resoluções do Seminário já afirmavam pautas que mais tarde seriam levantadas na luta do MNRU ao elencarem entre os direitos fundamentais do homem, o direito à habitação que ao exigir limitações ao direito de propriedade e uso do solo, se consubstanciaria numa reforma urbana conjunto de medidas estatais, visando à justa utilização do solo urbano, à ordenação e ao equipamento das aglomerações urbanas e ao fornecimento de habitação digna a todas as famílias.

Com o golpe militar, ocorrido em 1964, as ideias sobre a Reforma Urbana foram deixadas de lado pelo regime autoritário. Mesmo assim, na década de 1970, ainda durante o tal regime, verificou-se o ressurgimento do debate acerca da necessidade, da importância e da urgência da reforma urbana, congregando novas questões, a exemplo do uso e da ocupação do solo urbano. Nesse contexto, os movimentos sociais urbanos reacenderam o debate sobre a questão urbana, ao passo em que reivindicavam o cumprimento da função social da propriedade, conforme destaca Klintowitz (2013).

Nesse contexto, destaca-se que os movimentos sociais se reorganizaram e puderam definir uma pauta de reinvindicações mais extensas, contando, inclusive, com a participação de outros atores, a exemplo de segmentos como profissionais liberais, entidades estudantis e sindicais e, até mesmo, de intelectuais. Já nos anos de 1980, diferentemente das duas décadas anteriores, o país se mostrava mais complexo com relação à problemática urbana, em alguma medida agravada pela crise fiscal e financeira do setor público brasileiro. Nesse período, a luta pela Reforma Urbana resultou na constituição do Movimento Nacional pela Reforma Urbana (MNRU), em 1987, no bojo dos debates e discussões em torno do processo de redemocratização brasileiro. De certa forma, o MNRU acreditava que suas pautas seriam incorporadas no novo arcabouço jurídico do país, expresso na nova Constituição brasileira, promulgada em 1988.

Na prática, a proposição constitucional, expressa na Emenda Popular da Reforma Urbana, originou, na Constituição de 1988, o capítulo da Política Urbana que contém os artigos 182 e 183 , certamente uma das principais conquistas dos movimentos sociais urbanos nesse período. Nesse contexto, destaca-se que a estruturação dos referidos artigos gira em torno da noção de função social da cidade e da propriedade, e que, em nenhum outro momento, houve inscrição, em uma constituição brasileira, de nenhuma pauta referente à política 
urbana, o que, por sua vez, confere extrema relevância ao Movimento Nacional pela Reforma Urbana. Assim, parte importante das demandas desse movimento passou a constituir um importante arcabouço, inclusive incorporando a noção de planejamento e de gestão participativa, de um lado; e modificando a noção de direito à propriedade, de outro.

Apesar da comprovada importância do MNRU, ele passou por mudanças após a promulgação da Constituição Federal de 1988, tendo, inclusive, mudado a sua denominação para Fórum Nacional pela Reforma Urbana (FNRU). Klintowitz (2013, p. 07) observa que "a reformulação decorreu da necessidade do movimento se preparar e corresponder ao processo institucional, que saiu fortalecido com a nova Constituição Federal". Ao longo dos anos de 1998 e 2001, o FNRU concentrou esforços no acompanhamento do processo de tramitação e de discussão do Estatuto da Cidade (Lei Federal no 10.257), que instituiu um conjunto de diretrizes e de instrumentos direcionados ao planejamento e à gestão das cidades.

Na prática, o Estatuto da Cidade incorporou princípios e instrumentos discutidos ao longo das últimas duas décadas. Ao mesmo tempo, o planejamento e a gestão urbana que, em décadas passadas, eram conduzidos a partir de métodos autoritários e não participativos, ganham novos contornos no bojo do Estatuto da Cidade, passando a representar importante instrumento de aproximação entre sociedade e Estado.

Por fim, destaca-se que é sintomática a importância que os movimentos sociais tiveram, primeiro, na contestação do padrão vigente de produção de políticas públicas no espaço urbano, marcada pela clássica apropriação de poucos em detrimento de uma produção coletiva do espaço social urbano. Segundo, na proposição de diretrizes e de instrumentos que sinalizaram para a alteração desse padrão, em que pese a necessidade e a importância da efetivação do direito à cidade e do alcance de maior justiça social. Nesse sentido, a seguir, será apresentada discussão acerca dos movimentos sociais contemporâneos e sua atuação na luta pela garantia do direito à cidade. 


\section{Movimentos Sociais Contemporâneos: entre a teoria e a} prática

No campo teórico-metodológico, é consenso a ideia de que não existe uma só teoria ou metodologia sobre os movimentos sociais. A literatura é ampla e contém múltiplos modelos de análises que, de fato, refletem a fragmentação do campo temático. Como chama a atenção Gohn (2012, p. 32), "isto tem levado ao ecletismo nas interpretações contemporâneas onde convivem teorias com focos diversos (culturalistas, materialistas, pós-coloniais, institucionalistas, etc.), as quais utilizam um repertório de categorias analíticas oriundas de diferentes matizes paradigmáticas". No entanto, conforme destaca Céli Pinto (2012, p. 129):

a história recente dos movimentos sociais e sua própria existência como construto teórico estiveram sempre associadas à sociedade civil e à esfera pública não oficial. Suas manifestações foram analisadas como reação ao político institucional, tanto nos regimes autoritários/totalitários como nos regimes democráticos.

Ou seja, apesar das teorias analisarem os movimentos sociais sob óticas diferenciadas, a essência/origem/natureza dos mesmos não é questionada. Nesse caso, o que se tenta explicar é o padrão de relacionamento com o Estado, o qual era colocado em polo oposto à sociedade, e esta, por sua vez, como uma alternativa ao Estado ${ }^{2}$. Questionando os limites da democracia representativa, os novos movimentos sociais demonstram que a ação política dos cidadãos pode, de fato, contribuir para a democratização da cultura política, bem como para a reinvenção dos padrões da relação Estado-sociedade. Daí porque inúmeros estudiosos da política, no Brasil e no mundo, ressaltam a necessidade de compatibilizar a democracia representativa e a participativa.

No Brasil, o poder de decisão garantido, legalmente, aos membros dos movimentos sociais a partir da Constituição de 1988, e posteriormente com o Estatuto da Cidade, permitiu a inserção de demandas específicas do Movimento Nacional pela Reforma Urbana e, mais especificamente, da área de habitação e de mobilidade na agenda dos diferentes níveis de governo (União, estados e municípios).

\footnotetext{
${ }^{2}$ Não é objetivo deste paper realizar uma discussão aprofundada acerca do conceito de Movimento Social, para maiores detalhes ver ARATO e COHEN, 1994; GOHN, 1997, 2008, 2012; MELUCCI, 2001.
} 
Sendo assim, o que se observa, ao longo das últimas décadas, é que o perfil dos movimentos sociais sofreu alterações, em grande medida relacionadas às importantes mudanças ocorridas no bojo do processo de redemocratização do país. Nesse contexto, a conjuntura política brasileira redefiniu a forma de relacionamento do Estado com os movimentos sociais, em geral, e com os populares, em particular. Diante disso, observa-se, na atualidade, novas relações com as políticas públicas e outros atores sociais e políticos.

Observa-se, ainda, que a atuação de novos atores de movimentos sociais, uma vez incorporados às diferentes instâncias estatais, resulta em formas de participação social também diversa, as quais têm provocado alterações no padrão da administração pública brasileira. Ou seja, as novas posições assumidas pelos movimentos sociais no cenário político-institucional (propositivas e ativas), consequência das instituições participativas, gerou um diálogo em redes com outros atores sociais. Estes passaram a ocupar os espaços de representação da sociedade civil organizada, não estando mais, por conseguinte, à margem do Estado. O legado de novas práticas é algo notório na sociedade brasileira, dado o exercício da cidadania a partir da participação cidadã nos canais e instrumentos de gestão. Nesse sentido, o aumento do conhecimento dos movimentos sociais sobre a máquina pública vem gerando a demanda pela consolidação de um governo mais ético, transparente e democrático.

Diante disso, a agenda do governo federal, durante o governo Lula, produziu a ampliação da organização de setores e segmentos de movimentos sociais, associações especializadas e representantes do direito à cidade democrática. Dessa forma, padrões de ação coletiva passaram a pautar a organização dos movimentos e, como consequência, ampliaram a mobilização em torno da política urbana. Dentro desse mesmo cenário, no contexto da realização da Copa do Mundo FIFA 2014, o governo federal passou a encontrar resistência por parte de atores externos e internos ao governo. Nesse caso, a ideia subjacente era de que a Copa não apenas invertia a lógica da administração pública como também introduzia um questionamento bastante conflituoso na sociedade brasileira: como investir em estádios se não existia a garantia dos direitos sociais e do direito à cidade?

Vale destacar que, no período pré-Copa, existia nas cidades brasileiras uma demanda em relação à formação de espaços de mobilização e participação acerca dessas temáticas, que 
ganharam relevo nacional a partir das manifestações de junho de 2013. Como lembra o Movimento Passe Livre ${ }^{3}$ São Paulo (2013, p. 14):

as revoltas de junho 2013, desencadeadas pela luta organizada pelo MPLSP contra o aumento das tarifas, não são algo inteiramente novo. Para começar a compreender esse processo é preciso que voltemos a, no mínimo, 2003, quando, em resposta ao aumento das passagens, iniciou-se em Salvador uma série de manifestações que se estenderam por todo o mês de agosto daquele ano, que ficou conhecida como a Revolta do Buzu.

Com o processo de preparação para a Copa do Mundo 2014, Vainer (2013, p. 37) destaca que se inicia um contexto de "megaeventos, meganegócios, megaprotestos". Segundo o autor, "não há como não reconhecer a conexão estreita entre os protestos em curso e o contexto propiciado pelos intensos e maciços investimentos urbanos associados à Copa do Mundo de 2014 e, no caso do Rio de Janeiro, também aos Jogos Olímpicos de 2016".

Nesse cenário, havia um contraponto entre as demandas historicamente reprimidas na área social (saúde, segurança, educação, por exemplo) e as prioridades definidas pelo poder público para a realização da Copa. Essas, por sua vez, de longe, não incorporavam tais demandas. Desse modo, parte da sociedade brasileira, tendeu a apoiar as manifestações contrárias à Copa. As principais reivindicações estavam diretamente relacionadas à relativa ausência dos serviços públicos e à qualidade de prestação dos mesmos. A exigência era por mecanismos capazes de fortalecer a democracia, de modo a consolidar um Estado social com capacidade de resolver ou, no mínimo, reduzir os graves problemas sociais.

Em junho de 2013, a população brasileira foi às ruas gritar por melhores condições de vida e lembrar aos governantes que "há de se reconhecer, ademais, que os conflitos sociais decorrem de um conjunto brutal de ilegalidades cometidas pelos poderes públicos deste país (União, estados e municípios), ao não fazerem valer, em concreto, os direitos consagrados constitucionalmente" (SOUTO MAIOR, 2013, p. 85).

Diante do cenário acima esboçado, tornou-se possível ratificar as ideias de Castells (2013) relacionadas aos movimentos sociais na contemporaneidade. Para o autor (2013, p. 157), "ao longo da história, os movimentos sociais foram e continuam a ser as alavancas da mudança social". Ele avança destacando que os movimentos sociais que surgiram pelo

\footnotetext{
${ }^{3}$ Conforme Secco (2013, p.76-77), "o MPL, organização horizontal e autonomista, mas dirigente, foi o ator mais importante na primeira fase dos protestos. Trata-se de movimento fundado em 2005 e existente em várias cidades, fruto do acúmulo de revoltas contra o aumento das tarifas de transporte público que ocorreram em 2003 em Salvador e, logo depois, em Florianópolis".
} 
mundo nos últimos anos apresentam uma série de características comuns, as quais são fruto da crise econômica estrutural (dada à crise financeira de 2008) e de uma crise de legitimidade (encolhimento do Estado de bem-estar social).

Para Castells (2013, p. 158), os movimentos sociais contam com uma "autocomunicação de massa, baseada em redes horizontais de comunicação multidirecional, interativa, na internet; e, mais ainda, nas redes de comunicação sem fio, atualmente a principal plataforma de comunicação em toda parte". Dessa forma, para o autor, os novos movimentos sociais apresentam características em comum, as quais, para melhor entendimento, foram sintetizadas no quadro 01:

\begin{tabular}{|c|c|}
\hline CARACTERÍSTICAS & DESCRIÇÃO \\
\hline $\begin{array}{l}\text { Conectados em redes de } \\
\text { múltiplas formas }\end{array}$ & $\begin{array}{l}\text { O uso das redes de comunição, da internet e dos telefones celulares é } \\
\text { essencial, mas a forma de conectar-se em rede é multimodal. Embora } \\
\text { esses movimentos geralmente se iniciem nas redes sociais da } \\
\text { internet, eles se tornam um movimento ao ocupar o espaço urbano. }\end{array}$ \\
\hline $\begin{array}{l}\text { Simultaneamente locais } \\
\text { e globais }\end{array}$ & $\begin{array}{l}\text { Começam em contextos específicos, por motivos próprios, } \\
\text { constituem suas próprias redes e constroem seu espaço público ao } \\
\text { ocupar o espaço urbano e se conectar as redes da internet. Também } \\
\text { são globais, pois estão conectados com o mundo inteiro, aprendem } \\
\text { com outras experiências e são estimulados por essas experiências. }\end{array}$ \\
\hline Tempo atemporal & $\begin{array}{l}\text { Geraram suas próprias formas de tempo, combinando dois tipos } \\
\text { diferentes de experiências. Por um lado, nos lugares ocupados, vivem } \\
\text { um dia após o outro, sem saber quando virá a expulsão. Por outro, } \\
\text { em seus debates referem-se a um horizonte de possibilidade } \\
\text { ilimitada. }\end{array}$ \\
\hline $\begin{array}{l}\text { Espontâneos em sua } \\
\text { origem, geralmente } \\
\text { desencadeados por uma } \\
\text { centelha de indignação }\end{array}$ & $\begin{array}{l}\text { A sua gênese se relaciona a um evento específico ou a um acesso de } \\
\text { aversão pelas ações dos governantes. }\end{array}$ \\
\hline Virais & $\begin{array}{l}\text { Seguem a lógica das redes da internet. Inspiram-se em mobilizações, } \\
\text { o que desencadeia a esperança da possibilidade de mudança. }\end{array}$ \\
\hline $\begin{array}{l}\text { Sem liderança e } \\
\text { horizontais }\end{array}$ & $\begin{array}{l}\text { As tomadas de decisão se dão em assembleias ou em comitês por } \\
\text { elas designados. }\end{array}$ \\
\hline Autorreflexivos & $\begin{array}{l}\text { Questionam-se, como movimento, e seus participantes, como } \\
\text { indivíduos, sobre o que são, o que desejam e o que pretendem } \\
\text { realizar, e que tipo de democracia e sociedade estão almejando. }\end{array}$ \\
\hline $\begin{array}{l}\text { Raramente } \\
\text { Programáticos }\end{array}$ & $\begin{array}{l}\text { Não se concentram em um único tema, projeto ou tarefa. Assim, são } \\
\text { movimentos sociais voltados para a mudança nos valores da } \\
\text { sociedade. }\end{array}$ \\
\hline
\end{tabular}

Quadro 01: Características dos Movimentos Sociais na Era da Internet. Fonte: Elaboração própria baseada em Castells (2013).

Em resumo, esse autor concebe que:

esses movimentos sociais em rede são novos tipos de movimento democrático - de movimentos que estão reconstruindo a esfera pública no espaço de autonomia constituído em torno da interação entre localidades e redes da internet, fazendo experiências com as tomadas de decisão com base em assembleias e reconstituindo a confiança como alicerce da 
interação humana. [...] Eles enfatizam as contradições entre uma democracia baseada no cidadão e uma cidade à venda pelo lance mais alto. [...] O legado dos movimentos sociais em rede terá sido afirmar a possibilidade de reaprender a conviver. Na verdadeira democracia (CASTELLS, 2013, p. 177).

Diante dessa concepção, realizou-se uma pesquisa, em Natal, buscando verificar a presença dessas características a partir da análise de quatro movimentos sociais urbanos que se fizeram presentes no contexto da Primavera de Junho na Cidade do Sol.

\section{Movimentos sociais urbanos em Natal: afinal, do que estamos}

\section{falando?}

A fim de alcançar o objetivo de traçar um panorama dos movimentos sociais urbanos em Natal/RN, a partir da pauta de reivindicação de grupos no contexto da jornada de junho de 2013, observou-se a necessidade de estabelecer um recorte para tal estudo, em vista da diversidade de movimentos que, possivelmente, poderiam ser objeto de análise.

O caminho metodológico já descrito explicitou um cenário nacional em que predominava a luta em torno dos direitos à moradia e à mobilidade urbana, o que conduziu o presente estudo a enfocar nos movimentos relacionados a esses temas em Natal/RN. Após a seleção das principais temáticas, um novo estudo do material jornalístico, agora a partir de 60 reportagens veiculadas na mídia local, evidenciou como principais movimentos relacionados à mobilidade e à moradia: o Comitê Popular da Copa Natal; a Associação Potiguar dos Atingidos pelas Obras da Copa; o Levante Popular da Juventude do Rio Grande do Norte e o Movimento de Luta nos Bairros, Vilas e Favelas (MLB - Natal). Dessa forma, ao longo do estudo, a análise do material jornalístico foi utilizada como escolha metodológica para a seleção da temática e dos movimentos a ser estudados.

Em um segundo momento, a partir da análise proposta, buscou-se revelar quais as características dos movimentos sociais urbanos de Natal/RN no período de 2013 a 2016. Para isto, tornou-se necessário, inicialmente, apresentar os referidos grupos no que tange, principalmente, à sua organização, luta e relações. As informações foram coletadas por meio de entrevistas semiestruturadas com representantes dos movimentos, bem como a partir da análise de dados secundários. 
O Comitê Popular da Copa - Natal, constitui-se como um grupo oriundo da Articulação Nacional dos Comitês Populares da Copa - ANCOP, presente nas 12 cidades que sediaram os jogos da Copa do Mundo FIFA 2014. O seu principal objetivo era estimular, nos governos municipais e estaduais, a garantia de um processo amplo e democrático de discussão acerca de qual deveria ser o legado dos megaeventos esportivos no Brasil.

No caso de Natal, pode-se destacar que a dinâmica de atuação do Comitê Popular, a partir do envolvimento de lideranças comunitárias, se deu de formas variadas, com destaque para: a participação e a promoção de debates, seminários e atos públicos com as secretarias municipais e estaduais envolvidas na realização do referido megaevento. Além dessas atividades, reuniões semanais nas quatro zonas administrativas da cidade, assim como a produção de materiais informativos e de documentos de denúncia podem ser citados. Esse conjunto de ações pode ser destacado enquanto estratégia utilizada para conscientizar a população acerca dos impactos que seriam gerados pelos projetos de mobilidade urbana. Conforme observa uma das representantes entrevistadas:

[...] então a gente teve que criar estratégias, teve movimento de rua, gente com faixa, o pessoal botou as placas de luto nas casas, nas lojas, tinha pontos de encontro, coisas para chamar atenção [...] entregava panfleto e flores. Fomos pensando coisas diferentes para chamar atenção da população para que as pessoas abrissem os olhos e começassem a enxergar que é bom que a gente possa ter a copa, ter algum beneficio que possa trazer, mas dessa forma ai, fica difícil a gente aceitar. A gente via que muitas pessoas não tinham ideia que era dessa forma, o que estava sendo feito, quais eram os problemas que estavam sendo criados. [ENTREVISTADO C].

O Comitê ainda utilizava a internet como meio para divulgar as suas reuniões e reivindicações, a exemplo do que expôs a representante entrevistada:

Normalmente, a gente conseguia falar com as lideranças comunitárias, e também, vamos dizer assim, via redes sociais, quem a gente podia atingir que se interessasse, que se interessaria para ir, mas assim [...] era via internet, não tinha meios de fazer de outras formas, era uma organização totalmente voluntária, tudo que precisava fazer era dessa forma, não tinha estrutura, não tinha suporte. [ENTREVISTADO D].

Essa mesma entrevistada apontou que a atuação dos grupos em Natal se deu de forma horizontal, em grande medida porque os comitês, segundo ela, não têm muita burocracia, a exemplo do que é necessário para se criar uma associação. Desse modo, os esforços puderam ser mais direcionados para a discussão política das questões relacionadas à Copa 2014. Além disso, durante as discussões realizadas pelos movimentos, outras temáticas se 
articularam à luta pelo direito à cidade, a exemplo do direito à moradia, as reivindicações de ciclistas e a proteção ambiental. Com relação à ocorrência de discussões em torno de outras temáticas, as entrevistadas afirmaram que:

Então, tem todo um processo de resistência que foi se dando em capítulo assim, e como eu digo, num são multidões não, são ações pontuais e são grupos que tem uma determinada atuação, os ambientalistas, que se junta com os da mobilidade, então, eu acho que esse é o grande legado do comitê nesse processo é ter juntado essas tribos nessa coisa que fortalece, e a gente está conectado, continua conectado. [ENTREVISTADO D].

Com relação a Engenheiro Roberto Freire, por exemplo, quando identificamos que o Parque das Dunas iria ser sacrificado, o que é que a gente fazia inicialmente? Primeiro fazia estudos, pegava informações sobre o que tinha aquilo ali. Uma das coisas importantes, o parque das Dunas é uma unidade de conservação de proteção integral, mas não é só isso, é uma reserva da biosfera da mata atlântica, para ser reserva na UNESCO, você teve que dizer que tem uma unidade da mata atlântica que é "assim e aquilo outro" e cuido dela assim. [...] Aí trouxemos representantes das comissões de CONAMA para cá, para ele ver o problema e discutir, do Comitê Nacional da Mata Atlântica, conseguimos trazer para cá para participar, então a gente teve grandes articulações assim para não ficar como uma lutazinha provinciana, a gente tinha capacidade de buscar, digamos, um suporte maior e buscamos. [ENTREVISTADO C].

Outro ator relevante nesse processo preparatório para a Copa do Mundo FIFA 2014, em Natal, foi a Associação Potiguar dos Atingidos pelas Obras da Copa - APAC, criada no Dia Internacional dos Direitos Humanos, 10 de dezembro de 2012. Tal informação se torna importante na medida em que a compreensão da atuação política dos movimentos requer que seja conhecido o momento em que estes são articulados e organizados, bem como, saber acerca da dinâmica das lutas que realizam a partir de sua criação (GUIMARÃES, 2013). No caso da APAC, o surgimento dessa associação foi resultado de iniciativas de lideranças comunitárias que se encontravam, à época, envolvidas em diversos movimentos sociais. Essa associação atuava como organismo jurídico que representava legalmente os atingidos pelas obras da Copa em Natal, uma vez que o Comitê Popular não era institucionalizado para exercer tal representação. No que tange às formas de mobilização da APAC em Natal, Guimarães (2013) destacou a utilização de instrumentos de comunicação de massa, a exemplo dos carros de som, e, principalmente, da comunicação verbal, dotada de uma maior capacidade de mobilização. O principal objetivo da APAC era defender os direitos individuais, difusos e coletivos dos seus associados, visando sempre o combate ao abuso, às ilegalidades e às improbidades administrativas que pudessem ter relação com a Copa do Mundo FIFA 2014. De acordo com uma das representantes entrevistadas da APAC: 
Surgiu nesse contexto da gente ter identificado que essa realmente era a principal demanda e como forma de organizar as pessoas que já estavam se juntando, na época a gente participou do comitê popular da copa, que foi um tipo de organização que teve, senão em todos, mas praticamente em todos os estados que tinha cidades sede da copa [...] mas o comitê era uma articulação, articulação de entidades, de pessoas, movimentos, e a gente achou importante formalizar a associação APAC até pra isso nos ajudar na questão jurídica, em algum momento a gente poderia precisar de uma pessoa jurídica pra determinadas ações e aí criamos e formalizamos. [ENTREVISTADO F].

Nesse caso, igualmente, ao longo das lutas relacionadas às obras da Copa do Mundo FIFA 2014, outras temáticas foram introduzidas às discussões, tornando os movimentos cada vez mais plurais, a exemplo da proteção ambiental, conforme expôs a entrevistada:

No meio disso, começou a se falar também nas obras da Roberto Freire, que ia entrar no Parque das Dunas, aí também o grupo se voltou para essa obra, que tinha até o 'lagarto folhiço', que eu não lembro o nome científico dele, mas só tem aqui e aí foi pra defesa do Parque das Dunas, então todas as pautas que tiveram a ver com megaevento, esse grupo que, inicialmente, se juntou pra falar sobre as desapropriações, passou a participar de todas essas pautas. [...] Mas é isso, é uma das coisas mais bonitas do processo todo, é ver que não foi uma coisa individualista, né, aquelas pessoas podem ter despertado porque aquilo no momento estava atingindo pessoalmente, mas elas não ficaram militando só nas desapropriações, toda pauta ambiental, toda pauta do turismo, elas se envolveram e hoje continuam envolvidas na pauta da cidade, então foi feito de um jeito realmente formador, foi realmente de despertar sobre o direito a cidade, de despertar pra participação política, pra participação social mesmo, muitos dos atores continuam atuando, acho que foi o principal, e ter visto que teve realmente impacto. [ENTREVISTADO F].

Desse modo, tanto o Comitê Popular, quanto a APAC tiveram atuação direta nas reivindicações em torno do direito à moradia e à mobilidade urbana em um momento anterior às obras preparatórias para os jogos da Copa do Mundo em Natal. Nesse sentido, nos dois casos, as articulações se iniciaram em um período prévio à Primavera de Junho, tendo ganhado força e se articulado a outras reivindicações a partir de junho de 2013. De acordo com as entrevistas realizadas com representantes dos dois grupos, os conflitos entre o ente municipal e a população tiveram início a partir da constatação da afetação direta de centenas de famílias em razão das obras de mobilidade da Copa, as quais provocariam desapropriações consideradas necessárias conforme o projeto originalmente concebido pela gestão municipal de 2008/2012 em Natal. Naquele momento, a forma de planejamento das obras de mobilidade se deu a partir de um modelo top down, ou seja, de cima para 
baixo, excluindo a sociedade do processo de formulação dos projetos. Segundo uma das representantes da APAC, os projetos:

Chegaram para a gente prontos. A gente tentou interferir neles. A elaboração, o município dizia que tinha contratado uma empresa e a empresa fez. Os representantes da prefeitura davam entrevistas dizendo que iria haver as obras e que as obras iriam ser nas regiões, nos bairros tal e tal, e a gente não sabia, [...] porque só se sabia o que era dito nas entrevistas, mas ninguém tinha acesso ao projeto. [ENTREVISTADA F].

Diante do contexto de desinformação e insegurança causado pela ausência de transparência por parte da gestão municipal do período 2008/2012 e a partir das notícias que chegavam da mídia local, os moradores que se viam diretamente atingidos pelo projeto passaram a fortalecer um movimento em busca de garantir os seus direitos por meio de uma alteração no projeto original. Diante disso, diversas ações conjuntas foram realizadas pela APAC e pelo Comitê Popular para pressionar o poder municipal por alterações. Dentre elas, ressaltase a importância do chamado "pacto pela efetivação dos direitos humanos na Copa 2014". Durante o período eleitoral de 2012, esses atores agiram estrategicamente, ou seja, aproveitaram o momento político para solicitar aos candidatos a chefe do executivo municipal que assinassem um termo de compromisso, com base no qual seriam definidas garantias relacionadas à transparência e ao acesso à informação, à publicização do orçamento e ao equilíbrio dos benefícios relacionados ao megaevento. Além disso, o termo continha itens relacionados à atenção aos direitos trabalhistas; à defesa do Despejo ZERO na realização da Copa; ao Repúdio à "cidade de exceção"; à Participação/Consultas Públicas, assim como a outras violações de Direitos Humanos.

Diante do exposto, restou claro que as alterações propostas por parte da população só foram alcançadas dada a sua mobilização, uma vez que a mesma se sentia prejudicada com o andamento dos projetos. Conforme destacou a representante do Comitê Popular:

[...] nós levamos a questão pros candidatos, pegamos um termo de compromisso com os candidatos, tanto no primeiro turno quanto no segundo turno, um termo comprometendo eles a se fosse eleito não desapropriaria, iria rever o projeto, e o prefeito que foi eleito, é uma coisa que a gente tem que reconhecer, ele cumpriu, ele mudou o projeto, por mais que os engenheiros da prefeitura insistissem em fazer aquele projeto, ele não, ele disse que de forma nenhuma, encontrassem outro caminho porque ele tinha assumido um compromisso com os moradores e ia manter. Isso aí ele leva todo crédito. [ENTREVISTADA D]. 
Nesse sentido, em 2013, a gestão iniciou-se com um termo de compromisso assinado durante a campanha eleitoral, induzindo a realização de alterações que equilibrassem o direito à moradia com a mobilidade urbana. $\mathrm{O}$ cumprimento de tal termo assegurou a Natal o título de única cidade sede da Copa do Mundo de 2014 que não passou por um processo de desapropriação para viabilizar projetos de mobilidade. Assim, evidenciou-se que as ações responsáveis pelas mudanças ocorridas em Natal tiveram como protagonistas os grupos diretamente atingidos por obras e intervenções públicas, os quais, por suas pautas semelhantes, uniram forças para o alcance da garantia do direito à moradia.

Além desses dois grupos, o cenário esboçado a partir das Jornadas de Junho, especificamente em Natal, evidenciou a atuação de dois outros movimentos: o Levante Popular da Juventude e o Movimento de Luta nos Bairros, Vilas e Favelas (MLB). O Levante Popular da Juventude, em nível nacional, organiza a sua luta a partir do meio estudantil, das periferias dos centros urbanos e dos setores camponeses, buscando ampliar o número de grupos formados por jovens em diferentes territórios e setores da sociedade. A sua luta ocorre em contraponto ao sistema capitalista-patriarcal-racista, envolvendo temáticas relacionadas à dominação entre culturas, destruição do meio ambiente, opressão e exploração de mulheres, assassinato da juventude negra, bem como contra o preconceito à causa homoafetiva.

Segundo a descrição presente no portal eletrônico ${ }^{4}$ do próprio grupo, o Levante se destaca pela inexistência de uma única bandeira prioritária. Em Natal, algumas pautas já foram alvos principais por parte do Levante, como a luta contra o aumento da passagem de ônibus na capital, em 2012, e a proibição de venda de alimentos por ambulantes na Universidade Federal do Rio Grande do Norte, em 2015. No que tange a este movimento, destacou Guimarães (2013, p. 102):

O Levante Popular da Juventude também se insere na luta pelo acesso a serviços e bens públicos e pela mobilidade urbana, sendo esta uma das bandeiras de luta pautadas em sua atuação na cidade de Natal. Isto ficou evidente em ocasião da greve dos rodoviários, em maio de 2012, na qual o Levante Popular da Juventude manifestou apoio à ampliação e fortalecimento da luta dos trabalhadores rodoviários de Natal para que esta fosse também uma luta pelo transporte público, enquanto direito social, e contra o aumento no valor da passagem de ônibus.

\footnotetext{
${ }^{4}$ http://levante.org.br/
} 
O último grupo a ser destacado trata-se do Movimento de Luta nos Bairros, Vilas e Favelas (MLB), o qual iniciou a sua articulação em abril de 2004 (GUIMARÃES, 2013). A luta desse movimento se relaciona com a discussão em torno da reforma urbana e do direito à moradia. De uma forma geral, questiona a propriedade privada que caracteriza o modo de produção capitalista. O principal meio de mobilização deste grupo são as ocupações, consideradas como um instrumento educativo que desperta atenção para a necessidade de organização. Nesse sentido, expôs Guimarães (2013, p. 121-122):

Nessa direção de construção da hegemonia, a retórica das lideranças do MLB no que concerne às estratégias adotadas pelo movimento no seio da luta política inspiram e sugerem ainda ação imediata e confronto direto. $\mathrm{Na}$ trajetória particular deste movimento, estratégias como ocupação/acampamento foram sendo construídas como ações intrínsecas à sua atuação política, a partir da realização de discussões periódicas nas comunidades sobre a situação daqueles que não possuem casas, seguido de levantamento das pessoas dispostas a integrar e realizar a ocupação, isto é, concordando em ocupar e acampar, literalmente, em alguma área da cidade como meio de pressionar e agilizar a conquista de casas.

Nesse sentido, igualmente ao caso do Levante Popular da Juventude, pode-se afirmar que, em nível local, a forma de mobilização do MLB segue a lógica da estratégia nacional. Durante a Jornada de Junho, especificamente, nenhuma ocupação foi registrada em Natal, entretanto, dois acampamentos posteriores ganharam destaque na mídia local: a ocupação de terreno da Rede Ferroviária em 2015 e de área em Zona de Proteção Ambiental por 280 famílias em 2016.

Vencida a etapa de caracterização dos movimentos sociais urbanos em Natal, parte-se, agora, para a construção do panorama desses movimentos, utilizando, para tanto, a referência de Castells (2013), a fim de estabelecer uma correspondência entre a sua concepção de movimentos sociais e as práticas observadas na experiência estudada.

Nesse sentido, o quadro a seguir apresenta a síntese dessa correspondência a partir dos dados coletados em campo. Para tanto, realizou-se a análise da característica dos movimentos sociais locais a partir dos traços apresentados por Castells (2013) e sistematizados no quadro 1. Entretanto, em virtude das especificidades encontradas, é preciso ressaltar que, nem sempre, a realidade natalense se acomodava completamente ao tipo esboçado por Castells (2013). Diante disso, tornou-se necessário criar classificações que permitissem a afirmação dos movimentos enquanto total $(T)$ ou parcialmente (P) 
compatíveis com as características esboçadas pelo autor. Além disso, foram encontradas realidades em que algumas características eram completamente ausentes em nível local, ao que se atribuiu a legenda $(A)$.

\begin{tabular}{|c|c|c|c|c|}
\hline CARACTERÍSTICAS & APAC & $\begin{array}{l}\text { COMITÊ } \\
\text { POPULAR }\end{array}$ & MLB & $\begin{array}{l}\text { LEVANTE } \\
\text { POPULAR }\end{array}$ \\
\hline Conectados em redes de múltiplas formas & $T$ & $\mathrm{~T}$ & $\mathrm{~T}$ & $\mathrm{~T}$ \\
\hline Simultaneamente locais e globais & $\mathrm{P}$ & $\mathrm{P}$ & $T$ & $\mathrm{~T}$ \\
\hline Tempo atemporal & $P$ & $P$ & $T$ & $T$ \\
\hline $\begin{array}{l}\text { Amplamente espontâneos em sua origem, geralmente } \\
\text { desencadeados por uma centelha de indignação }\end{array}$ & $T$ & $\mathrm{~T}$ & $T$ & $T$ \\
\hline Virais & $T$ & $\mathrm{~T}$ & $\mathrm{~T}$ & $T$ \\
\hline Sem liderança e horizontais & $\mathrm{P}$ & $\mathrm{P}$ & $\mathrm{P}$ & $P$ \\
\hline Autorreflexivos & $P$ & $P$ & $T$ & $T$ \\
\hline Raramente Programáticos & A & A & $T$ & $\mathrm{~T}$ \\
\hline
\end{tabular}

Quadro 02: Características dos Movimentos Sociais Pesquisados em Natal. Fonte: Elaboração própria (2016). Nota: $P$ = Parcial; $T$ = Total; $A=$ Ausente.

Com base no quadro acima, constatou-se o estabelecimento de dois padrões de movimentos sociais urbanos em Natal. O primeiro padrão, formado pelo MLB e o Levante Popular apresenta uma maior quantidade de características que definem os movimentos sociais na contemporaneidade à luz da construção teórica de Castells. O segundo, por sua vez, contém menos características definidoras desses movimentos, fazendo parte desse padrão a APAC e o Comitê Popular. Ressalta-se que os quatro atores sociais pesquisados são considerados como movimentos sociais em redes, sobretudo por apresentarem um intenso uso das redes de comunicação nos seus processos (mobilização, reivindicação, contestação e discussões, por exemplo).

No tocante ao cotidiano da ação política dos movimentos e organizações populares de Natal, apreende-se que dentre as estratégias adotadas pelos movimentos estudados, é comum a adoção de abaixo-assinados, manifestos ou atos públicos e a utilização do diálogo e da comunicação verbal, além do uso de instrumentos de comunicação de massa. Quanto a isso, uma dificuldade que pode ser verificada a partir do depoimento dos entrevistados, tratou-se da restrita atenção da imprensa local no apoio à divulgação dos trabalhos realizados pelos movimentos sociais, o que, de certa forma, impulsionou a ampla utilização das redes sociais. Entretanto, deve ser destacado que apenas dois movimentos (MLB e LPJ) utilizam, como forma de ação política, as estratégias de ocupação.

Outra característica verificada se relaciona a origem desses movimentos, a qual se deu de modo espontâneo nos quatro casos. Porém, no caso da APAC e do Comitê Popular, esse 
surgimento está vinculado a questões mais pontuais, ou seja, a experiência vivenciada em razão da Copa. Já o MLB e o LPJ possuem origem a partir de questões mais ampliadas.

Dessa forma, foram identificadas duas tendências vinculadas a projetos políticos distintos. 0 MLB e o Levante Popular da Juventude apresentam intenções de rompimento com o status quo, sinalizando para a perspectiva de construção de uma nova sociabilidade. Conforme observado, esses dois movimentos são plurais desde a sua concepção, de forma que, em seus debates, tocam temáticas diversas em prol da construção de uma cidade socialmente justa. Esses dois movimentos, portanto, demonstraram não possuir uma bandeira única prioritária.

No que se refere à APAC e ao Comitê Popular, pode-se afirmar que esses demonstram estar ligados a uma ideologia de participação, pautada na lógica do associativismo, na qual a sociedade precisa se organizar para buscar meios necessários à resolução de problemas mais imediatos. Considera-se, assim, que esses dois últimos movimentos possuem uma ideologia e um projeto político crítico à atual lógica societária, mas não incorporam a perspectiva de superação desta ordem em sua proposta política (GUIMARÃES, 2013). Além disso, os seus debates giram em torno de questões pontuais, embora, se articulem, ao longo de sua trajetória, com discussões relacionadas a temáticas priorizadas por outros movimentos presentes no espaço urbano de Natal, a exemplo das questões ambientais. Esses movimentos ainda se caracterizam por sua baixa autorreflexividade, justamente, pelo seu viés momentâneo e a sua pauta restrita a interesses específicos.

No que tange à horizontalidade dos movimentos pesquisados, constatou-se que, em todos eles, apesar da existência de processos deliberativos, há, em contraponto, uma dependência em relação a uma liderança que conduz a organização interna e a comunicação externa.

Nesse sentido, encontrou-se, localmente, um cenário marcado por movimentos diversos no contexto de um mesmo espaço urbano. Apesar de se concentrarem na discussão da mobilidade e do direito à moradia, foram constatadas pautas de reivindicação mais amplas em alguns casos (MLB e LPJ), além de distintas formas de atuação na cena urbana. 


\section{Considerações finais}

Diante da discussão realizada, qual seria, portanto, a conexão guardada entre os movimentos sociais urbanos no cenário brasileiro, e tantos outros espalhados no ambiente internacional como a Primavera Árabe, os Indignados na Espanha e dos Estudantes no Chile? Como destaca Rolnik (2013), todos esses movimentos transformaram praças em palcos de protestos, em sua grande maioria eram movimentos compostos por jovens, que se mobilizavam por meio das redes sociais, sem a presença de partidos, sindicatos e organizações em geral.

A Primavera de Junho no Brasil aconteceu "sem que ninguém esperasse. Sem líderes. Sem partidos nem sindicatos em sua organização. Sem apoio da mídia. Espontaneamente. Um grito de indignação [...] por meio da ocupação das ruas em manifestações que reuniram multidões em mais de 350 cidades" (CASTELLS, 2013, p. 178). Nesse contexto, assistiu-se, portanto, o modo de fazer política ser colocado em cheque no país.

O fato é que, como chama a atenção Castells (2013, p. 74) "esses vários movimentos surgiram de causas específicas a cada país e evoluíram de acordo com as condições de seus contextos e das idiossincrasias de cada revolta. Mas todos eles foram levantes espontâneos". Percebe-se, portanto, a prevalência de similaridades no que tange ao modo de atuação dos movimentos nacionais e internacionais, ou seja, "convocações pela internet, constituição de redes no ciberespaço e apelos pela ocupação do espaço urbano para pressionar o governo" (CASTELLS, 2013, p. 74).

A ideia de traçar um panorama dos movimentos sociais urbanos, em Natal/RN, a partir do contexto da Primavera de Junho de 2013, possibilitou evidenciar características diversas desses movimentos. Considerando o exposto, convem destacar que, apesar da temática central referir-se ao Direito à Cidade, não foi possível verificar, na análise dos movimentos sociais contemporâneos em Natal, a ocorrência de processos e de dinâmicas semelhantes aos que ocorreram nas décadas de 1970 e 1980 quando eram fortemente abordadas questões relacionadas ao direito à cidade, no contexto do Movimento Nacional pela Reforma Urbana.

No período recente, se verificam referências ao Direito à Cidade na pauta de reinvidicações de alguns movimentos sociais. No entanto, a prática desses movimentos tem revelado o 
predomínio de questões mais pontuais de atendimento a determinadas demandas, em geral localizadas, e menos a uma discussão e a uma construção coletiva de estratégias de ação com vista à efetivação do direito à cidade, na perspectiva da apropriação coletiva dos valores de uso complexo do espaço urbano.

Sendo assim, a partir da identificação das diferenças na atuação dos movimentos em Natal, pode-se vislumbrar um cenário que, conforme exposto, se assemelha ao contexto intenacional citado por Castells (2013), mas que, internamente, se mostra dividido em dois tipos de movimentos sociais. O primeiro tipo pode ser caracterizado pelo enfoque em questões pontuais. Nesse caso, predominam práticas que denotam a busca pela resolução de questões específicas, a exemplo das obras de mobilidade da Copa de 2014. A referência dessas práticas eram questões mais relacionadas a famílias que poderiam ser afetadas por essas obras, e menos uma agenda comum visando à construção de uma ação coletiva mais perene, em prol de uma cidade mais justa e democrática.

Já o segundo tipo de movimento verificado na cidade do Natal, por sua vez, caracteriza-se por uma agenda mais ampliada, difusa e atemporal, assim como a realização de eventos específicos, a exemplo da Copa do Mundo. Integra esse segundo tipo os movimentos MLB e Levante Popular da Juventude.

Nesse sentido, constatou-se que, apesar do pressuposto que guiou o presente estudo, a realidade estudada demonstrou uma diversidade de configurações, que impossibilita a afirmação de que os movimentos sociais urbanos de Natal não estabelecem diálogo entre si, são momentâneos e não horizontais. Conforme indicado, a pesquisa evidenciou a ocorrência de convergências de ações entre os movimentos sociais em momentos oportunos. Por outro lado, explicitou-se que, no cenário local, existem movimentos que possuem uma atuação pontual e focalizada, enquanto outros realizam debates amplos e não possuem uma única bandeira prioritária. Por fim, confirmou-se um dos aspectos apontados: todos os movimentos pesquisados contam com lideranças definidas, que conduzem as atividades internamente.

Com relação a tal aspecto, compreende-se que, em grande medida, embora os movimentos locais sigam interconectados com os movimentos praticados no país, diferentemente do que têm sido apontado quanto aos movimentos nacionais e internacionais no que tange a 
sua horizontalidade, encontrou-se, localmente, movimentos que demonstram certa dependência com relação a líderes que conduzem a organização e a comunicação desses movimentos.

É preciso pontuar que, no contexto da Copa do Mundo, abriu-se uma janela de oportunidades para o fortalecimento desses quatro movimentos, a qual não foi completamente aproveitada, uma vez que todos eles se envolveram em ações nas áreas de mobilidade e moradia, mas deixaram de promover uma articulação perene em torno de suas pautas.

No seio dessa discussão, fica evidente que as manifestações de Junho de 2013 , bem como o aprofundamento das reivindicações nas capitais sede dos jogos da Copa, contaram com a atuação de grupos diversos em suas características. Porém, de modo geral, eles encontram guarida na discussão em torno dos movimentos sociais em rede (CASTELLS, 2013), apresentando aspectos que possibilitam a afirmação de uma nova forma de fazer política.

Desse modo, apresentou-se a atuação de movimentos que, a partir da Primavera de Junho de 2013, iniciaram a construção de um legado, o qual consiste na "possibilidade de reaprender a conviver. Na verdadeira democracia" (CASTELLS, 2013, p. 177). Portanto, eles evidenciaram outro formato de atuação capaz de realizar transformações na esfera pública e, consequentemente, na gestão democrática da cidade.

\section{Referências bibliográficas}

CARDOSO, Adauto L. A cidade e seu estatuto: uma avaliação urbanística do Estatuto da Cidade. In RIBEIRO, Luiz Cezar de Q.; CARDOSO, Adauto L. Reforma urbana e gestão democrática: promessas e desafios do Estatuto da Cidade. 2a edição. Rio de Janeiro: Revan/Fase, 2012.

CASTELLS, Manuel. Redes de indignação e esperança: movimentos sociais na era da internet. Rio de Janeiro: Zahar, 2013.

FERREIRA, João S. W. O processo de urbanização brasileiro e a função social da propriedade ubana. In Curso à Distância: Planos Locais de Habitação de Interesse Social. Ministério das Cidades, Brasília/DF, 2009.

GOHN, Maria da Glória. Movimentos sociais no início do século XXI: antigos e novos atores sociais. Petrópolis, RJ: Vozes, 2010.

GOHN, Maria da Glória; BRINGEL, Breno M. Movimentos sociais na era global. Petrópolis, RJ: Vozes, 2012.

GUIMARÃES, M. C. R. Movimentos sociais e organização popular em Natal-RN: enquanto morar for privilégio. 2013. Mestrado em Serviço Social. Universidade Federal do Rio Grande do Norte, 2013. 
GRAZIA, Grazia de. Reforma Urbana e estatuto da cidade. In RIBEIRO, Luiz Cezar de Q.; CARDOSO, Adauto L. Reforma urbana e gestão democrática: promessas e desafios do Estatuto da Cidade. 2a edição. Rio de Janeiro: Revan/Fase, 2012.

KLINTOWITZ, Danielle C. O Movimento Nacional de Reforma Urbana e a Construção de uma Política Nacional de Desenvolvimento Urbano Pós-Redemocratização: da Cooptação à Estruturação de um funcionamento de Decoupling. In Anais do XV Encontro Nacional da ANPUR. Recife: ANPUR, 2013.

LAVALLE, Adrian Gurza.; VERA, Ernesto Isunza. A trama da crítica democrática: da participação à representação e à accountability. Lua Nova, v. 84, p. 353-64, 2011.

MIGUEL, Luis Felipe. Representação política em 3- D: elementos para uma teoria ampliada da representação política. Revista Brasileira de Ciências Sociais. Fev., vol.18, no. 51, p.123- 140, 2003.

MIGUEL, Luis Felipe. Democracia e representação: territórios em disputa. 1ạ ed. São Paulo: Editora Unesp, 2014.

MOVIMENTO PASSE LIVRE - SÃO PAULO. Não começou em Salvador, não vai terminar em São Paulo. In MARICATO, Ermínia et al. Cidades Rebeldes: Passe livre e as manifestações que tomaram as ruas do Brasil. São Paulo: Boitempo: Carta Maior, 2013.

PINTO, Celi R. J. Movimentos Sociais 2011: estamos frente a uma nova forma de fazer política? In GOHN, Maria da Glória; BRINGEL, Breno M. Movimentos sociais na era global. Petrópolis, RJ: Vozes, 2012.

ROLNIK, Raquel. As vozes das ruas: as revoltas de junho e suas interpretações. In MARICATO, Ermínia et al. Cidades rebeldes: Passe Livre e as manifestações que tomaram as ruas do Brasil. São Paulo: Boitempo: Carta Maior, 2013.

SOUTO MAIOR, Jorge L. A vez do direito social e da descriminalização dos movimentos sociais. In MARICATO, Ermínia et al. Cidades Rebeldes: Passe livre e as manifestações que tomaram as ruas do Brasil. São Paulo: Boitempo: Carta Maior, 2013.

VAINER, Carlos. Quando a cidade vai às ruas. In MARICATO, Ermínia et al. Cidades rebeldes: Passe Livre e as manifestações que tomaram as ruas do Brasil. São Paulo: Boitempo: Carta Maior, 2013.

YOUNG, Iris Marion. Representação política, identidades e minorias. In: Revista Lua Nova. São Paulo, 67, p. 139-190. 2006. 